\title{
Enhancement of the killing effect of low- temperature plasma on Streptococcus mutans by combined treatment with gold nanoparticles
}

\author{
Sang Rye Park', Hyun Wook Lee ${ }^{2}$, Jin Woo Hong ${ }^{3}$, Hae June Lee ${ }^{4}$, Ji Young Kim', Byul bo-ra Choi', \\ Gyoo Cheon $\mathrm{Kim}^{5^{*}}$ and Young Chan Jeon ${ }^{6 *}$
}

\begin{abstract}
Background: Recently, non-thermal atmospheric pressure plasma sources have been used for biomedical applications such as sterilization, cancer treatment, blood coagulation, and wound healing. Gold nanoparticles (gNPs) have unique optical properties and are useful for biomedical applications. Although low-temperature plasma has been shown to be effective in killing oral bacteria on agar plates, its bactericidal effect is negligible on the tooth surface. Therefore, we used 30-nm gNPs to enhance the killing effect of low-temperature plasma on human teeth.

Results: We tested the sterilizing effect of low-temperature plasma on Streptococcus mutans (S. mutans) strains. The survival rate was assessed by bacterial viability stains and colony-forming unit counts. Low-temperature plasma treatment alone was effective in killing S. mutans on slide glasses, as shown by the 5-log decrease in viability. However, plasma treatment of bacteria spotted onto tooth surface exhibited a 3-log reduction in viability. After gNPs were added to $S$. mutans, plasma treatment caused a 5-log reduction in viability, while gNPs alone did not show any bactericidal effect. The morphological changes in $\mathrm{S}$. mutans caused by plasma treatment were examined by transmission electron microscopy, which showed that plasma treatment only perforated the cell walls, while the combination treatment with plasma and gold nanoparticles caused significant cell rupture, causing loss of intracellular components from many cells.

Conclusions: This study demonstrates that low-temperature plasma treatment is effective in killing S. mutans and that its killing effect is further enhanced when used in combination with gNPs.
\end{abstract}

Keywords: Gold nanoparticle, Low-temperature plasma, Streptococcus mutans, Sterilization, Oral care

\section{Background}

Dental caries is a chronic infection of worldwide prevalence, and it represents oral health problems associated with oral bacteria [1]. Although remarkable technical developments have been made in dental treatment, dental caries remains a major oral health problem in most countries [2]. Dental caries commonly occur on the occlusal and proximal surfaces of the tooth, particularly in its pits and fissures. These sites are structurally difficult to approach when treating a decayed tooth. In clinical management, a carious tooth is simply removed by

\footnotetext{
* Correspondence: ki91000m@pusan.ac.kr; jeonyc@paran.com

${ }^{5}$ Department of Oral Anatomy, School of Dentistry, Pusan National University, Yangsan 602-739, Rep. Korea

${ }^{6}$ Department of Dental Prosthetics, School of Dentistry, Pusan National University, Yangsan 602-739, Republic of Korea

Full list of author information is available at the end of the article
}

dental handpiece drilling, after which a restorative material is used to fill the empty space. During this process, a greater amount than necessary of healthy tooth tissue is often removed along with the decayed part. Furthermore, if the cavity is filled without completely removing bacteria, the remaining bacteria cause recurrence of dental caries. Therefore, a novel method that strongly inhibits the causative pathogens regardless of their spatial accessibility to hand-held tools and decreases the excessive removal of the healthy parts of the tooth is highly desirable.

Low-temperature atmospheric pressure plasma has been used for biomedical applications such as sterilization, cancer treatment, blood coagulation, and wound healing [3]. Since plasma generates high amounts of reactive oxygen species (ROS) and hydroxyl radicals 
$(\cdot \mathrm{OH})$, it is highly effective in killing bacteria such as Escherichia coli, Candida albicans [4,5], Pseudomonas aeruginosa [6], and Lactobacillus casei [7]. The bactericidal property of non-thermal plasmas has been recently used against oral pathogens. Effective killing of Enterococcus faecalis has been reported using low-frequency air plasma and pulse-modulated He plasma needles [8]. A microwave plasma pencil has been reported to induce a high death rate of Streptococcus mutans with $\mathrm{H}_{2} \mathrm{O}_{2}$ [9]. However, plasma treatment alone needs a relatively long time for killing $S$. mutans $[9,10]$.

S. mutans, a facultative anaerobic [11] and high acidproducing bacterium [12], has been identified as the principal cause of dental caries. Acidic substances produced by $S$. mutans destroy the dental enamel, leading to severe tooth decay. Plasma treatment has been reported to induce a high death rate of S. mutans. However, in those studies, the plasma temperature was too high for application to human tissues. [13,14]. Being gram-positive, $S$. mutans has a thick cell wall to protect it from the external environment. This thick cell wall makes it more difficult to kill gram-positive than gramnegative bacteria. Furthermore, the presence of grampositive bacteria in very narrow crevices of a tooth limits their accessibility for various treatments. In this study, gold nanoparticles (gNPs) were used to enhance the killing effect of low-temperature plasma on S. mutans. Because of the high electric conductivity of gNPs, we assumed that they could be activated by plasma. Stimulated gNPs would then cause high levels of cellular stress, which could lead to the death of the bacteria. The aim of this study was to enhance the killing effect of low-temperature plasma on $S$. mutans by means of gNPs for dental caries treatment.

\section{Results}

Enhancement of the killing effect of plasma by using gNPs

To investigate the killing effect of plasma, a cover glass was coated with $5 \mu \mathrm{L}\left(\sim 10^{8}\right.$ colony-forming units (CFUs)/mL) of a suspension of $S$. mutans. The survival curve showed a 5-log reduction in cell viability by plasma treatment for $300 \mathrm{~s}$. Using gNPs attached to $S$. mutans cells in combination with plasma treatment yielded a $6-\log$ reduction in viability (Figure 1 ). The killing effect of plasma on $S$. mutans cannot be due to a thermal effect because the plasma temperature did not exceed $37^{\circ} \mathrm{C}$ for longer than $5 \mathrm{~min}$ (Figure 2).

The killing effect of plasma on S. mutans cells was lower for cells spotted onto the surface of the tooth than for cells on a cover glass. To enhance the bactericidal effect, gNPs were employed. After the addition of gNPs to $S$. mutans for $1 \mathrm{~h}$, plasma treatment significantly decreased the viability of $S$. mutans cells. Plasma-only treatment of S. mutans cells for $300 \mathrm{~s}$ showed a 3-log reduction, while cells treated with gNPs and plasma exhibited a 5-log decrease (Figure 3). The difference in the killing effect with plasma only and combination treatment with gNPs and plasma was statistically significant $(p<0.05)$.

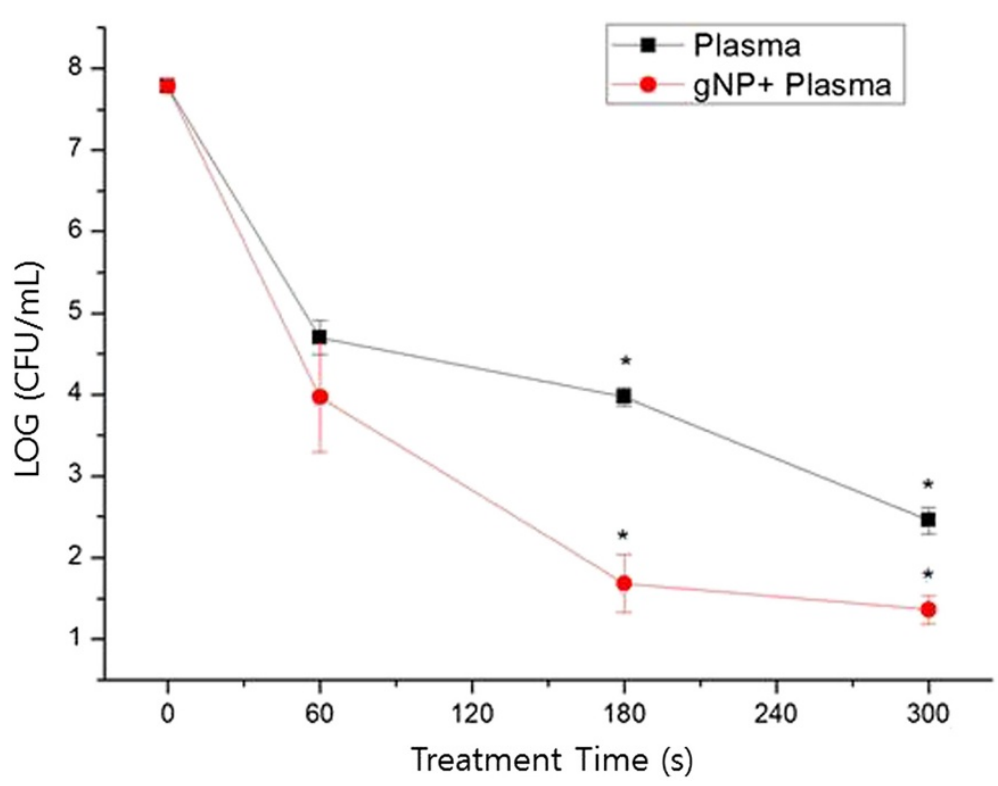

Figure 1 Enhanced killing effect can be achieved using combined gold nanoparticle (gNP) and low-temperature plasma treatment for Streptococcus mutans cultured on a cover glass. Bacterial viability was assessed by plate counting. The difference between the death rates for plasma-only and plasma plus gNPs was statistically significant $(p<0.05)$. 


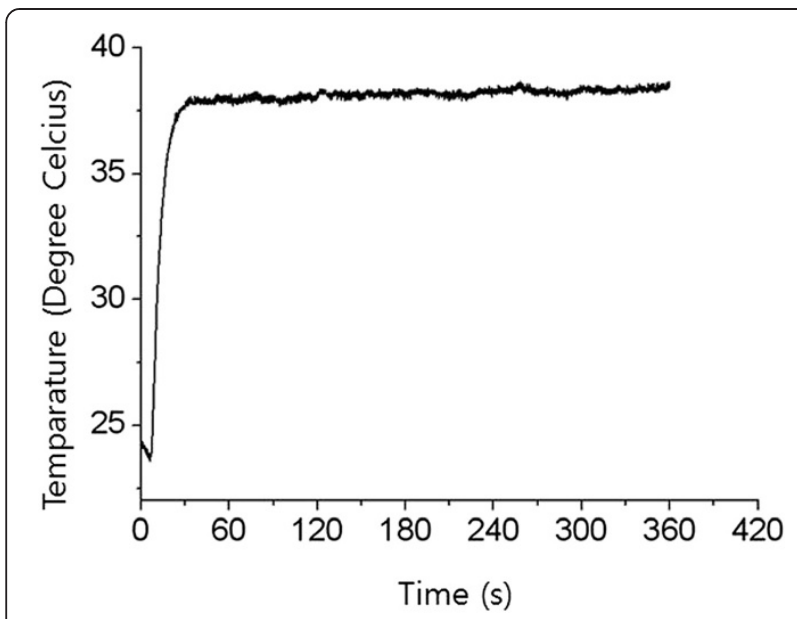

Figure 2 The temperature of the plasma jet was measured $8 \mathrm{~mm}$ away from the end of the plasma source with an argon flow rate of 2.5 standard liters per minute.

\section{Viability staining of $S$. mutans cells}

The viability of $S$. mutans was analyzed using fluorescence microscopy. S. mutans was stained with SYTO $9^{\circ}$ and propidium iodide (PI). SYTO $9^{\circ}$ (green fluorescence) can label all living bacteria in a population, whereas PI (red fluorescence) can only penetrate bacteria with damaged membranes, which causes a decrease in SYTO $9^{\circ}$ fluorescence intensity. Control cells and bacteria treated only with gNPs showed green fluorescence (Figure 4A and B), while red fluorescence was detected in S. mutans cells treated with microwave plasma for $60 \mathrm{~s}$ (Figure 4C). The combination treatment of plasma and gNPs showed only a few green fluorescent cells (live), which were detected among mostly red fluorescent cells (dead) (Figure 4D).

\section{Morphological examination of cell damage by transmission electron microscopy}

Using transmission electron microscopy (TEM), we analyzed the morphological changes in S. mutans cells after plasma treatment. The cell membrane was smooth, and cell division was observed in the control experiment (Figure 5A). After plasma treatment, the cell membrane and cell wall were disrupted, but the cytosol was retained within the cell (Figure 5B). After addition of gNPs, which bind to the cell wall of $S$. mutans, the plasma treatment significantly ruptured the cell walls (Figure $5 \mathrm{C}$ ) and led to the release of its cytoplasmic components (Figure 5D).

\section{Discussion}

This study demonstrates that gNPs enhance the killing effect of low-temperature plasma on S. mutans. Conventionally, oral antiseptic agents have been widely used to reduce the number of oral bacteria. However, their usage for long periods might lead to side effects such as tooth staining, dry mouth, and taste disturbance [15]. Currently, lasers are being used in many fields of dentistry, including caries treatment [16]. A laser beam is an intense, coherent, and highly directional beam of light. These characteristics of lasers are of limited benefit for cavity treatment in a tooth with a curved surface and an irregular shape. For instance, in the case of periapical

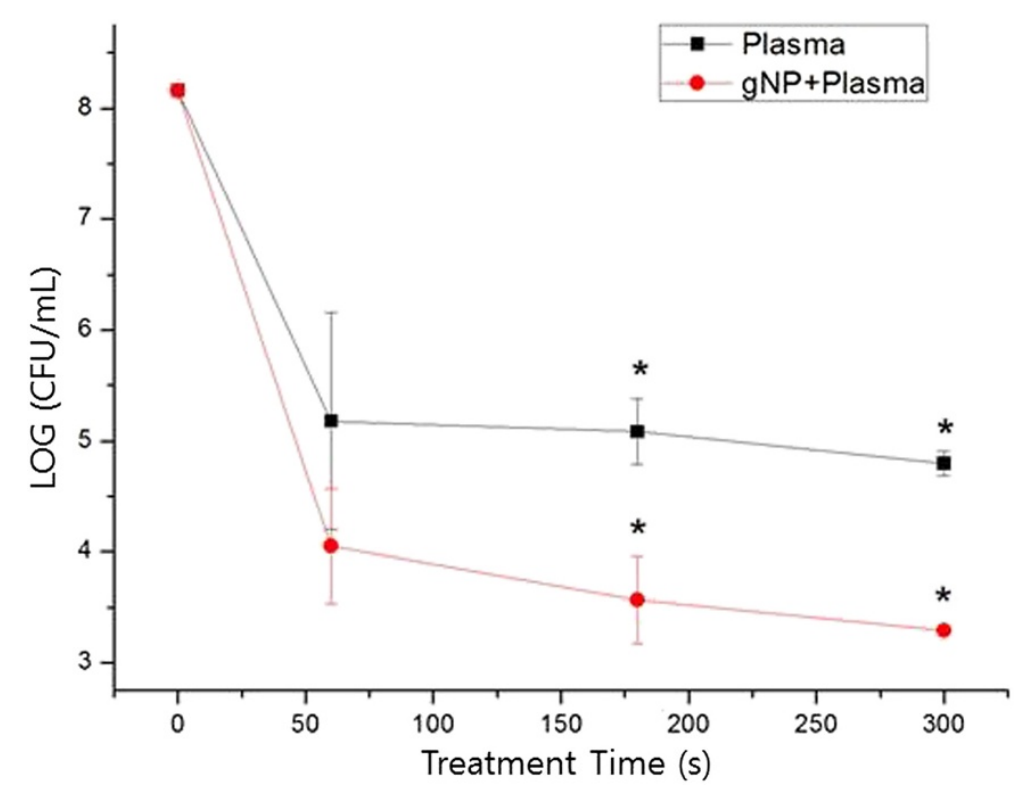

Figure 3 Enhanced killing effect can be achieved using a combination of gNPs and low-temperature plasma treatment for S. mutans on the tooth. Bacterial viability was typically assessed by plate counting. The difference between the death rate of $S$. mutans by using plasma alone and that by using plasma plus gNP is statistically significant $(p<0.05)$. 


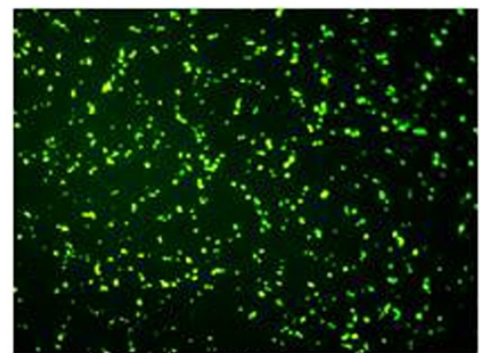

(A)

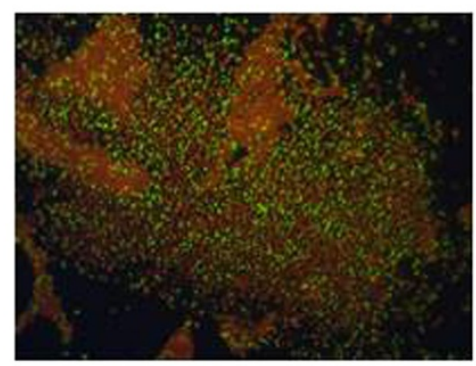

(C)

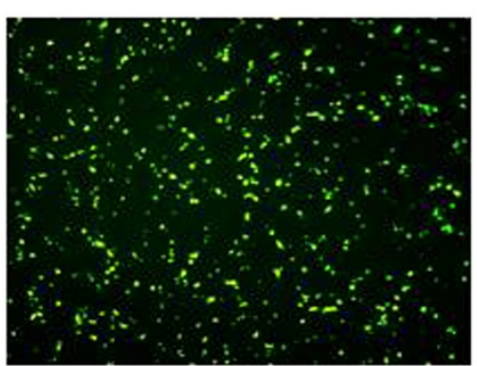

(B)

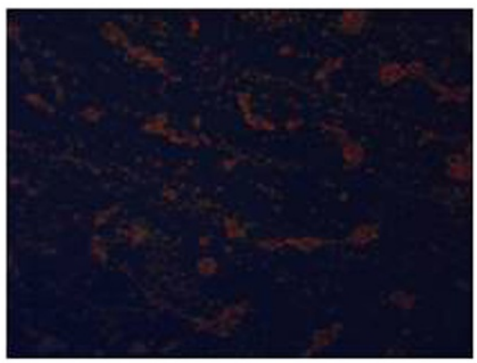

(D)

Figure 4 Viability staining of S. mutans cells. (A) Untreated control cells. (B) S. mutans cells treated with gNPs. (C) S. mutans cells treated with plasma only. (D) S. mutans cells treated with gNPs and plasma. All treatments were applied for $30 \mathrm{~s}$, and cells were stained with SYTO 9 and propidium iodide. Images were observed under a fluorescence microscope (magnification, $\times 400$ ).

infections, it is difficult to apply laser beams to the infection site. However, plasma is an ionizing gas, which results in high flexibility for application to various oral structures and for overcoming such spatial limitations. Thus, plasma can easily approach an infection site and effectively kill oral pathogens.

Although many studies have been carried out to determine the mechanism of killing by plasma, the exact mechanism is not yet clearly understood. This might be due to the multitude of plasma-generated components such as ROS, charged particles, and electrostatic and electromagnetic fields. Thus, it is possible that several components work together to produce a synergistic effect rather than a single component contributing to the sterilization. Plasma can produce a large amount of ROS when it passes through air, and in particular, high levels of $\bullet \mathrm{OH}$ are generated when plasma reacts with water or tissue fluid. It is well known that $\cdot \mathrm{OH}$ effectively kills

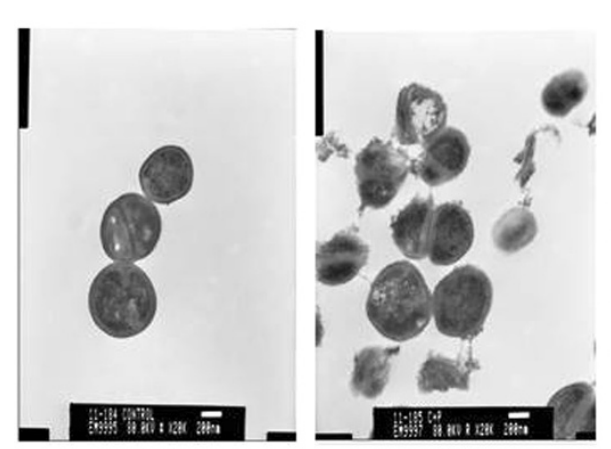

(A)

(B)

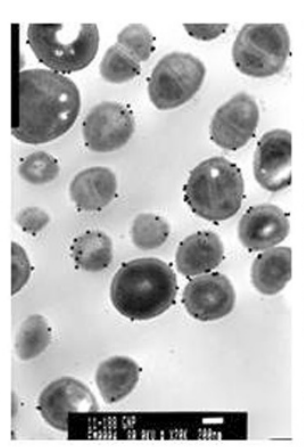

(C)

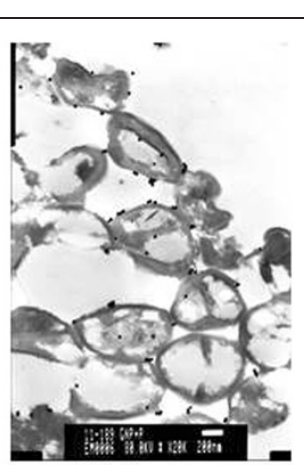

(D)

Figure 5 Transmission electron microscopy images of $S$. mutans treated with low-temperature plasma and gNPs $(\times 20,000)$. (A) Control cells without any treatment. (B) S. mutans cells treated with plasma only. (C) S. mutans cells treated with gNPs only. (D) Morphological features of S. mutans cells after combined treatment with plasma and gNPs. 
bacteria. Furthermore, the half-life of plasma-generated ROS is very short, and hence, its retention in the oral cavity is short and less likely to induce harmful effects on tissues. Although the plasma is called low-temperature plasma, plasma gas generates heat, which should not lead to thermal damage to tissues. In other articles reporting the killing effect of plasma, thermal damage could be observed owing to the high temperature of plasma [13,14]. Considering that temperatures higher than $42.5^{\circ} \mathrm{C}$ induce pulpal damage, the plasma temperature should be maintained below $40^{\circ} \mathrm{C}$. As shown in Figure 2, the temperature of the plasma used in this experiment did not exceed $37^{\circ} \mathrm{C}$ for longer than $5 \mathrm{~min}$. Thus, plasma-induced thermal damage to the oral tissues was unlikely.

In this study, plasma treatment showed a $5-\log$ reduction in $S$. mutans cells on the cover glass. This significant bactericidal effect decreased to a 3-log reduction when $S$. mutans was grown on the tooth surface. Although a 3-log reduction of $S$. mutans obviously represents a high bactericidal effect, the residual bacteria could cause recurrent dental caries. Accordingly, as a new method to overcome this issue, we used gNPs in combination with low-temperature plasma to achieve a high level of effectiveness and rapid killing of S. mutans. In this study, we used $30-n m$ colloidal shaped gNPs. gNPs are well known for biosafety and uptake into the cell [17]. The shape and size of gNPs can be easily controlled [18], which has led to their widespread application in diagnostics [19], therapeutics, and drug delivery [20]. According to one study, the electric field at the adhesion point between gNPs and membrane was amplified when gNPs attached to the surface of a nuclear membrane were exposed to plasma [21]. In an earlier study by our group, we showed that gNPs stimulated by plasma induced selective cancer cell death in melanoma and oral squamous carcinoma cells $[22,23]$. In the current study, gNPs were bound to $S$. mutans cells walls, and no alterations were observed in the $S$. mutans cells. Plasma treatment of $S$. mutans was more effective against gNP-attached cells than against the gNP-free ones. TEM images showed severe cell wall damage with plasma treatment. Furthermore, the combination treatment of gNPs and plasma led to cell wall rupture, such that most intracellular components were released. This finding suggests that the plasma energy, which may have been amplified by gNPs, could induce severe stress to the $S$. mutans cell walls. The most likely mechanisms of the synergistic effect of the microwave plasma and gNPs might be enhanced electric field and local heating near the gNPs. High electric conductivity and the nano-size geometry of the gNPs lead to electric field concentration on gNPs [21-23]. The enhanced electric field near the gNPs might attract or repel charged particles. This could cause ion bombardment from the plasma [24] and gathering of charged particles inside bacteria, leading to the rupture of the cell wall. Joule heating of the gNPs can be an important factor. An earlier study showed high thermal power dissipation of gold by a radio frequency electric field, and it increased as the size of gNPs decreased [25]. These suggestions can explain the severe damages to the bacteria cell walls.

Considering these data, the use of gNPs in combination with plasma has proven very effective in killing the bacteria hidden in the very small spaces of the tooth. Therefore, this technique can limit the number of bacteria remaining within the tooth structure and markedly decrease the recurrence of dental caries.

The microwave plasma jet has a resonator structure. Most of the microwave power is consumed for sustaining the plasma and is reflected at the open end of the microwave plasma source [26]. Only little microwave power can leak from the microwave plasma source. A low E-field has been found to exist near the open end, and the E-field intensity reduces exponentially as the distance increases [27]. This indicates that the effect of microwave leakage on patients is negligible.

\section{Conclusions}

Low-temperature plasma can be applied to various tooth structures for therapy and preventive dentistry. Furthermore, plasma-stimulated gNPs attached to S. mutans significantly destroyed the cells walls, thereby promoting cell death. We suggest that the technique using plasma and gNPs could be a good method for dental caries treatment in dental clinics.

\section{Methods}

\section{Plasma source}

Microwave driven-atmospheric pressure plasma was employed for killing S. mutans. The plasma source was based on the coaxial transmission line resonator [26], and it generated a low-temperature plasma jet. It was operated by a palm-size power module [28] with a $2.5 \mathrm{~W}$ net input power. Argon gas was supplied to the plasma source through a flow meter (KOFLOC, Ar-05). We covered the end of the plasma source with an acrylic cap that had a smaller output area (diameter of output hole, $2 \mathrm{~mm}$ ) than the plasma source. The stability of the plasma jet at the acrylic cap increased without change in the characteristics of the plasma (Figure 6).

\section{Temperature measurement}

Generally, microwave-driven plasma has high temperatures. However, by using a very low operating power $(2.5 \mathrm{~W})$ and adjusting the gas flow, we could obtain lowtemperature plasma. Under constant input power, the temperature of the plasma jet was dependent of the gas flow rate. The temperature of the plasma jet was 


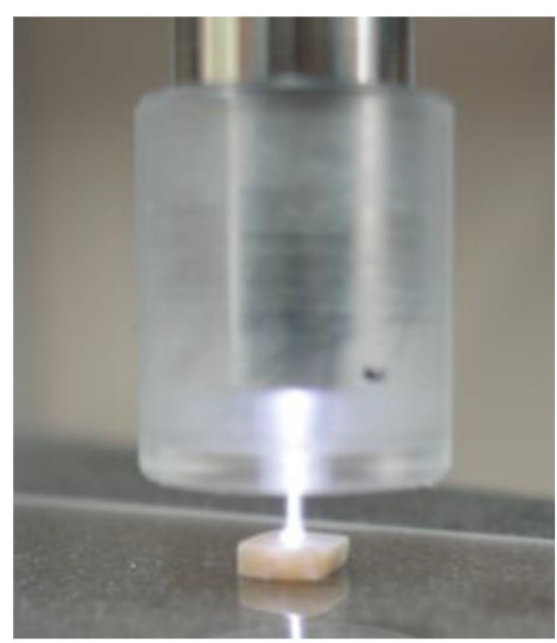

(A)

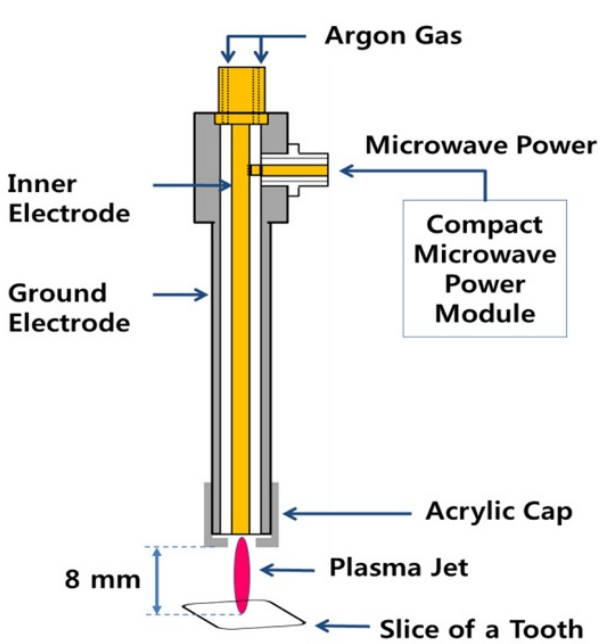

(B)

Figure 6 Microwave plasma device and plasma jet. (A) Microwave plasma source and (B) schematic diagram of the plasma device and the experimental set up.

measured using a The temperature of the plasma jet was measured using a thermometer with an optical fiber probe (FTI-10, FISO Technologies). The probe was located $8 \mathrm{~mm}$ away from the end of the plasma source, and the plasma jet contacted the probe. The location of the probe coincided with the location of the target tooth in the sterilization experiment. The maximum temperature reached was $41.1^{\circ} \mathrm{C}$, and it decreased to $37^{\circ} \mathrm{C}$ in $5 \mathrm{~min}$ (Figure 2). The gas flow rate was set to 2.5 standard liters per minute. The length and diameter of the plasma jet were approximately $8 \mathrm{~mm}$ and $2 \mathrm{~mm}$, respectively.

\section{Tooth slicing and sample preparation}

Tooth slices of $2 \mathrm{~mm}$ thickness and approximately $3 \mathrm{~mm}$ diameter were cut from extracted human molars with a low-speed diamond saw (Struers, Copenhagen, Denmark). The exposed tooth surface was smoothened with Sic abrasive paper with grinding (grit P 120, 800, 1200). Subsequently, the tooth slices were cleaned for $10 \mathrm{~min}$ in the ultrasonic cleaner, autoclaved at $121^{\circ} \mathrm{C}$ for $15 \mathrm{~min}$, and stored in phosphate-buffered saline (PBS). Five microliters of the $S$. mutans solution was spotted onto the tooth surface and allowed to dry out for $15 \mathrm{~min}$ at room temperature. The distance between the plasma jet and the tooth surface was $8 \mathrm{~mm}$. The contamination on the tooth surface was plasma-treated for $60 \mathrm{~s}, 180 \mathrm{~s}$, and $300 \mathrm{~s}$. After plasma treatment, the tooth slices were vortexed for $30 \mathrm{~s}$ in $1 \mathrm{~mL}$ PBS, and $100 \mu \mathrm{L}$ of these samples was inoculated onto agar plates in a 10 -fold serial dilution. The agar plates were incubated at $37^{\circ} \mathrm{C}$ for $24 \mathrm{~h}$ before the colonies were counted (IRB No. 05-2012-023).

\section{Treatment of bacteria on cover glass}

S. mutans on cover glass were treated with non-thermal plasma. All conditions were performed in the same manner as in experimental tooth slices.

\section{Bacterial strains and culture conditions}

The strain of S. mutans (KCTC 3065/ATCC 25175) was grown in brain heart infusion (BHI) broth (Fluka, Switzerland). S. mutans was cultivated overnight in liquid media incubated at $37^{\circ} \mathrm{C}$, and the cells were diluted with PBS to a final concentration of approximately $10^{8}$ CFUs/mL.

\section{Preparation of gNPs}

Effective binding of S. mutans was achieved using 30-nm colloidal gNPs. S. mutans cells were cultured in BHI broth medium for $24 \mathrm{~h}$ at $37^{\circ} \mathrm{C}$ and harvested by centrifugation at $4,000 \mathrm{rpm}$ for $5 \mathrm{~min}$ at $4^{\circ} \mathrm{C}$. The supernatant was discarded, and $10 \mathrm{mM}$ sodium bicarbonate $(\mathrm{pH}=8.8)$ was added to the gNPs to resuspend them. S. mutans cells were added to the gNPs and incubated for $1 \mathrm{~h}$ at $37^{\circ} \mathrm{C}$. Subsequently, they were centrifuged at $4^{\circ} \mathrm{C}$ for $5 \mathrm{~min}$ at 4,000 rpm. The supernatant was discarded, and sodium bicarbonate buffer was used for the final suspension solution.

\section{Bacterial viability staining}

After the plasma treatment, S. mutans was stained with the nucleic acid stains SYTO $9^{\circ}$ (Invitrogen-Molecular Probes, OR, USA) and PI (Sigma Aldrich, MO, USA) according to the manufacturer's instructions. Cells were 
visualized and classified as live or dead by fluorescence microscopy (Axioskop; Zeiss, Germany).

\section{Transmission electron microscopy}

Bacterial samples for TEM imaging were fixed with 2.5\% glutaraldehyde for $2 \mathrm{~h}$ at $4{ }^{\circ} \mathrm{C}$ and then incubated with $1 \%$ osmium tetroxide for $1 \mathrm{~h}$ at $4^{\circ} \mathrm{C}$. After the cells were rinsed, dehydrated in ethanol, and infiltrated with propylene oxide, they were embedded in Epon. Ultrathin sections were stained with uranyl acetate and lead citrate and observed using TEM at Electron microscopy Facility, Department of Ophthalmology, Pusan National University Hospital (JEM 1200EX-II; JEOL, Japan).

\section{Statistical analysis}

Statistical analysis was performed using SPSS (SPSS version 18 for Windows, SPSS Inc., USA). The logarithmic values of each bacterial plate count were calculated and analyzed using the Student's $t$-test. A $p$-value less than 0.05 was considered statistically significant.

\section{Abbreviations}

BHI: Brain heart infusion; CFU: Colony-forming unit; gNP: Gold nanoparticle; PBS: Phosphate-buffered saline; PI: Propidium iodide; TEM: Transmission electron microscopy.

\section{Competing interests}

The authors declare that they have no competing interests.

\section{Authors' contributions}

HJL analyzed the data, and YCJ contributed in collecting tooth samples. SRP, $H W L$, and BRC carried out the laboratory experiments and analyzed the data. GCK provided technical input and devised the project idea. SRP and GCK wrote the manuscript. JYK contributed to interpretation of data. All authors read and approved the final manuscript.

\section{Acknowledgements}

This study was supported by the Medical Research Institute Grant (2011-22), Pusan National University Hospital.

\section{Author details}

'Department of Dental Hygiene, Kyungnam College of Information and Technology, Busan 617-701, Rep. Korea. ²Department of Electrical Engineering, Pohang University of Science and Technology, Pohang 790-784, Rep. Korea. ${ }^{3}$ Department of Korean Internal Medicine, School of Korean Medicine, Pusan National University, Yangsan 626-870, Korea. ${ }^{4}$ Department of Electronics Engineering, Pusan National University, Busan 609-735, Rep. Korea. ${ }^{5}$ Department of Oral Anatomy, School of Dentistry, Pusan National University, Yangsan 602-739, Rep. Korea. ${ }^{6}$ Department of Dental Prosthetics, School of Dentistry, Pusan National University, Yangsan 602-739, Republic of Korea.

Received: 22 May 2014 Accepted: 1 August 2014

Published: 8 August 2014

\section{References}

1. Petersen PE, Bourgeois D, Ogawa H, Estupinan-Day S, Ndiaye C: The global burden of oral diseases and risks to oral health. Bull World Health Organ 2005, 83:661-669.

2. Shinada K, Ueno M, Konishi C, Takehara S, Yokoyama S, Kawaguchi Y: A randomized double blind crossover placebo-controlled clinical trial to assess the effects of a mouthwash containing chlorine dioxide on oral malodor. Trials 2008, 9:1-8.

3. Kalghatgi S, Kelly CM, Cerchar E, Torabi B, Aleksee O, Fridman A, Friedman G, Clifford JA: Effects of non-thermal plasma on mammalian cells. PLoS ONE 2011, 6:1-11.
4. Koban I, Geisel MH, Holtfreter B, Jablonowski L, Hübner NO, Matthes R, Masur K, Weltmann KD, Kramer A, Kocher T: Synergistic effects of nonthermal plasma and disinfecting agents against dental biofilms in vitro. ISRN Dentistry 2013, 2013:1-10.

5. Kvam E, Davis B, Mondello F, Gamer AL: Nonthermal atmospheric plasma rapidly disinfects multidrug-resistant microbes by inducing cell surface damage. Antimicrob Agents Chemother 2012, 56:2028-2036.

6. Yang L, Chen J: Low temperature argon plasma sterilization effect on Pseudomonas aeruginosa and its mechanisms. J Electrostatics 2009, 67:646-651.

7. Rupf S, Lehmann A, Hannig M, Schafer B, Schubert A, Feldmann U, Schindler A: Killing of adherent oral microbes by a non-thermal atmospheric plasma jet. J Med Microbiol 2010, 59:206-212.

8. Pei $X, L u X$, Liu J, Liu D, Yang Y, Ostrikov K, Chu PK, Pan Y: Inactivation of a $25.5 \mu \mathrm{m}$ Enterococcus faecalis biofilm by a room-temperature, batteryoperated, handheld air plasma jet. J Phys D Appl Phys 2012, 45:1-5.

9. Lee HW, Lee HW, Kang SK, Kim HY, Won IH, Jeon SM, Lee JK: Synergistic sterilization effect of microwave-excited nonthermal Ar plasma, $\mathrm{H}_{2} \mathrm{O} 2$, $\mathrm{H} 2 \mathrm{O}$ and $\mathrm{TiO}_{2}$, and a global modeling of the interactions. Plasma Sources Sci Technol 2013, 22:1-11.

10. Molnar I, Papp J, Simon A, Anghel SD: Deactivation of Streptococcus mutans biofilms on a tooth surface using he dielectric barrier discharge at atmospheric pressure. Plasma Sci Technol 2013, 15:535-541.

11. Hamada S, Masuda N, Kotani S: Isolation and serotyping of Streptococcus mutans from teeth and feces of children. J Clin Microbiol 1980, 11:314-318.

12. Yang B, Chen J, Yu Q, Lin M, Mustapha A, Hong L, Wang Y: Oral bacterial deactivation using a low-temperature atmospheric argon plasma brush. J Dent 2011, 39:48-56.

13. Vargo Jj: Clinical applications of the argon plasma coagulator. Gastrointest Endosc 2004, 59:81-88

14. Fridman $G$, Peddinghaus $M$, Ayan $H$, Fridman A, Balasubramanian M, Gutsol A, Brooks A, Fredman G: Blood coagulation and living tissue sterilization by floating-electrode dielectric barrier discharge in air. Plasma Chem Plasma Process 2006, 26:425-442.

15. Tamura S: Effects of oral streptococci on biofilm formation by cariogenic bacteria in dual species cultures. Kokubyo Gakkai Zasshi 2008, 75:38-48.

16. Ghadimi S, Chiniforush N, Bouraima SA, Johari M: Clinical approach of laser application in different aspects of pediatric dentistry. J Lasers Med Sci 2012, 3:84-90

17. Spivak YS, Bubnov RB, Yemets LM, Lazarenko LM, Tymoshok NO, Ulberg ZR: Gold nanoparticles - the theranostic challenge for PPPM: nanocardiology application. EPMA J 2013, 4:1-17.

18. Kong MG, Keidar M, Ostrikov K: Plasmas meet nanoparticles-where synergies can advance the frontier of medicine. J Phys D Appl Phys 2011, 44:174018.

19. Huang CJ, Chiu PH, Wang YH, Yang CF: Synthesis of the gold nanodumbbells by electrochemical method. J Colloid Interface Sci 2006, 303:430-436.

20. Cheng J, Gu YJ, Cheng SH, Wong WT: Surface functionalized gold nanoparticles for drug delivery. J Biomed Nanotechnol 2013, 9:1362-1369.

21. Tiwari PK, Kang SK, Kim GJ, Choi J, Mohamed AAH, Lee JK: Modeling of Nanoparticle-mediated electric field enhancement inside biological cells exposed to AC electric Fields. Jpn J Appl Phys 2009, 48:087001-087007.

22. Kim GC, Kim GJ, Park SR, Jeon SM, Seo HJ, Iza F, Lee JK: Air plasma coupled with antibody-conjugated nanoparticles: a new weapon against cancer. $J$ Phys D Appl Phys 2009, 42:32005-32009.

23. Choi BB, Choi YS, Lee HJ, Lee JK, Kim UK, Kim GC: Nonthermal plasmamediated cancer cell death; targeted cancer treatment. J Therm Sci Tech 2012, 7:399-404.

24. Ostrikov K, Neyts EC, Meyyappan M: Plasma nanoscience: from nano-solids in plasmas to nano-plasmas in solids. Adv Phys 2013, 62:1-110.

25. Moran CH, Wainerdi SM, Cherukuri TK, Kittrell C, Benjamin J, Wiley BJ, Nicholas NW, Curley SA, Kanzius JS, Paul Cherukuri P: Size-dependent joule heating of gold nanoparticles using capacitively coupled radiofrequency fields. Nano Res 2009, 2:400-405.

26. Choi J, Iza F, Do HJ, Lee JK, Cho MH: Microwave-excited atmosphericpressure micro plasmas based on a coaxial transmission line resonator. Plasma Sources Sci Technol 2009, 18:1-8.

27. Lee HW, Kang SK, Won $\mathrm{H}$, Kim HY, Kwon HC, Sim JY, Lee JK: Distinctive plume formation in atmospheric Ar and He plasmas in microwave 
frequency band and suitability for biomedical applications. Phys Plasmas 2013, 20:1-13.

28. Park SJ, Choi J, Park GY, Lee SK, Cho YS, Yun JI, Jeon SM, Kim KT, Lee JK: Inactivation of S.mutans using an atmospheric plasma driven by a palm-size-integrated microwave power module. IEEE Trans Plasma Sci 2010, 38:1956-1962.

doi:10.1186/s12951-014-0029-5

Cite this article as: Park et al.: Enhancement of the killing effect of low-temperature plasma on Streptococcus mutans by combined treatment with gold nanoparticles. Journal of Nanobiotechnology 2014 12:29.

\section{Submit your next manuscript to BioMed Central and take full advantage of:}

- Convenient online submission

- Thorough peer review

- No space constraints or color figure charges

- Immediate publication on acceptance

- Inclusion in PubMed, CAS, Scopus and Google Scholar

- Research which is freely available for redistribution 